\title{
Có một nhóm người Việt đang giúp Nhật Bản phát triển bền vững
}

\author{
Phạm Trần Hải
}

Giáo dục Việt Nam

$11 / 12 / 201906: 00$

(GDVN; https://giaoduc.net.vn/giao-duc-24h/co-mot-nhom-nguoi-viet-dang-giup-nhat-ban-phat-trienben-vung-post205241.gd) - Mặc dù viết về một thành phố Nhật Bản, nhưng cả 4 tác giả đều là người Việt, trong đó có 3 người đang là học viên cao học và nghiên cứu sinh tại Nhật Bản.

LTS: Trong khi người Việt chúng ta thường chi quen với việc người nước ngoài đến Việt Nam để giúp các giải pháp khoa học và kỹ thuật, giúp phát triển kinh tế - xã hội thì đâu đó, trong một số bối cảnh khác, đã có những trường hợp thành công theo chiều ngược lại.

Bài viết dưới đây của tác giả Phạm Trần Hải, hiện đang công tác tại Văn phòng Thành ủy Hải Phòng và là cựu du học sinh tại Nhật Bản giới thiệu một công trình khoa học của một nhóm tác giả Việt Nam (hiện đang sống tại Nhật Bản và Việt Nam), giúp góp phần cung cấp luận cứ khoa học cho việc phát triển bền vững về môi trường tại chính Kitakyushu.

Lần đầu đặt chân tới thăm Kitakyushu khi còn là du học sinh tại Nhật Bản cách đây 4 năm, tôi không thể tin thành phố này từng bị che mờ bởi bụi bặm từ ống khói của các nhà máy công nghiệp nặng bởi lẽ khung cảnh công nghiệp đã được phủ thêm màu xanh của cây và những ngọn đồi.

Không chỉ có vậy, sự phát triển của khoa học và công nghệ tại đây, mà nổi bật là trường Đại học Kitakyushu-xếp thứ 79 trên Nhật Bản theo Tạp chí Times, càng khiến tôi choáng ngợp hơn về sức sống của thành phố này.

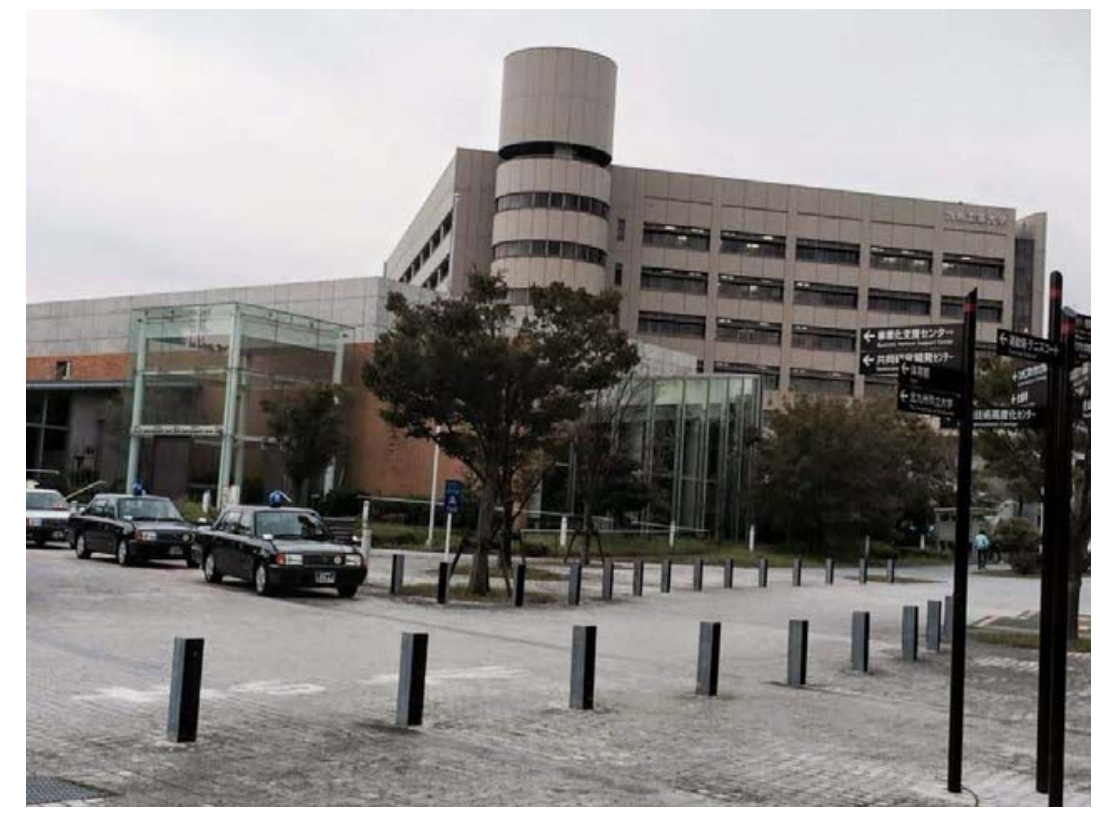


Một góc Kitakyushu (Ảnh do tác giả cung cấp)

Kitakyushu có lẽ là đại diện tiêu biểu cho nỗ lực biến đổi từ một thành phố công nghiệp nặng trở thành một lá phổi xanh của khu vực Kyushu và Nhật Bản.

Cũng phải thôi, vì đây là một trong năm thành phố trên thế giới được chọn làm thí điểm cho dự án các thành phố kiểu mẫu SDG (Sustainable Development Goal - Mục tiêu phát triển bền vững - sáng kiến do Liên hợp quốc khởi xướng từ 2015) tại các quốc gia OECD, đồng thời cũng là đại diện duy nhất tại Châu Á.

Bài báo về chủ đề phát triển bền vững tại Kitakyushu đăng trên tạp chí uy tín

Trở về Việt Nam sau thời gian học tập, tôi vẫn giữ thói quen đọc tin tức liên quan tới Nhật Bản cũng như liên lạc với các bạn học người Việt cũ tại Kitakyushu.

Một bài báo thú vị về Kitakyushu mới được đăng trên tạp chí Palgrave Communications [ $\mathrm{ESCl}$; CiteScore $2018=0.88$ ] thuộc hệ thống Nature Research xuất bản đã khiến tôi chú ý, vì cả nội dung lẫn vì trong nhóm tác giả có những người là bạn học cũ tại Nhật của tôi.

Bài báo có tên gọi The trilemma of sustainable industrial growth: evidence from a piloting OECD's Green city (DOI: https//doi.org/10.1057/s41599-019-0369-8) (tạm dịch Bộ ba bất khả thi của phát triển công nghiệp bền vững: bằng chứng từ việc thử nghiệm một thành phố xanh của $\mathrm{OECD}$ ) mới được đăng trên Plagrave Communications đầu tháng 12/2019 vừa qua đã công bố kết quả phân tích từ gần nửa thế kỷ dữ liệu của thành phố Kitakyushu.

Nó cho thấy sự phức tạp và khó khăn để đạt được mục tiêu phát triển bền vững. Các chính sách "xanh" và việc thúc đẩy phát triển ngành công nghiệp tái chế có thể giúp thành phố đạt được mục tiêu phát triển công nghiệp và giảm thải ô nhiễm không khí và khí nhà kính.

Tuy nhiên, hệ thống giao thông được mở rộng phục vụ cho phát triển công nghiệp tái chế, lại dẫn đến ô nhiễm không khí gây ra do gia tăng số lượng phương tiện giao thông cá nhân và việc đô thị hóa tràn lan.

Kết quả nhấn mạnh sự quan trọng của việc hợp tác - phối hợp giữa chính quyền, giới công thương, và người dân để đạt được mục tiêu phát triển bền vững. 
nature $>$ palgrave communications $>$ articles $>$ article

MENU $\vee$ palgrave

communications

Article | Open Access | Published: 03 December 2019

\title{
The trilemma of sustainable industrial growth: evidence from a piloting OECD's Green city
}

\author{
Quan-Hoang Vuong, Manh-Tung Ho $\square$, Hong-Kong To Nguyen \& Minh-Hoang \\ Nguyen $\square$ \\ Palgrave Communications 5, Article number: 156 (2019) | Cite this article \\ 21 Altmetric | Metrics
}

\begin{abstract}
Hình ảnh bài báo

Để có được khung cảnh môi trường như hiện nay, Kitakyushu đã phải trải qua một hành trình rất lâu dài, với sự nỗ lực của nhiều cơ quan, đoàn thể trong thành phố.

Có lẽ vì thế mà các tác giả của nghiên cứu cũng đã trải qua nhiều khó khăn để có thể đưa bài báo về đích. Được biết, bản thảo đã bị từ chối nhiều lần trước khi đến với độc giả, trên một ấn phẩm thuộc Nature Research.

\section{Tâm nguyện của một người Việt trẻ}

Mặc dù viết về một thành phố Nhật Bản, nhưng cả 4 tác giả đều là người Việt, trong đó có 3 người đang là học viên cao học và nghiên cứu sinh tại Ritsumeikan Asia Pacific University (APU), thành phố Beppu, tỉnh Oita, Nhật Bản (Nguyễn Minh Hoàng, Hồ Mạnh Tùng, Nguyễn Tô Hồng Kông ; người còn lại hiện đang công tác tại Trung tâm ISR, trường Đại học Phenikaa, Hà Nội (Tiến sĩ Vương Quân Hoàng).

Một trong hai tác giả liên hệ của nghiên cứu là Nguyễn Minh Hoàng cũng là người tôi thường xuyên giữ liên lạc sau khi về nước.

Khi còn cùng ở bên Nhật, trong những lần có có dịp tâm sự, Hoàng thường xuyên nói với tôi về mong ước được làm một cái gì đó cho Nhật Bản, đất nước đã gắn bó với Hoàng từ những năm tháng đại học tới tận bây giờ. Và với bài báo ý nghĩa này, tôi hiểu là Hoàng đã hoàn thành tâm nguyện của mình, theo một cách rất riêng.
\end{abstract}

\section{Nỗ lực hội nhập quốc tế trong khoa học}


Ngay sau khi đọc được thông tin bài báo, tôi đã gửi thư chúc mừng Hoàng. Để từ đó, tôi cũng hiểu thêm về nỗ lực của Hoàng và cộng sự trong việc quyết tâm tiến hành nghiên cứu theo chuẩn mực quốc tế.

Hoàng tâm sự, theo dõi những diễn biến mới nhất về đào tạo tiến sĩ và bổ nhiệm giáo sư, phó giáo sư ở trong nước hiện nay, Hoàng hiểu là bằng tiến sĩ ở nước ngoài, kể cả ở một đại học uy tín như APU cũng mới chỉ là điều kiện cần giúp bạn có thể phát triển sự nghiệp nghiên cứu sau khi về nước.

Một trong những điều kiện đủ mà Hoàng muốn hướng tới, ngay từ khi còn là nghiên cứu sinh tại Nhật là đã có những công trình được công bố trên các tạp chí uy tín quốc tế. Và bài báo mới đăng này là một trong những thành quả mới nhất của Hoàng.

Hoàng kể lại với tôi: "Trong thời gian làm bài, em cảm thấy rất vất vả vì em coi đây là cơ hội kiểm tra năng lực và chất lượng suy nghĩ của mình và cả nhóm nghiên cứu.

Đồng thời, vì các tạp chí mà nhóm nghiên cứu ngắm tới có chất lượng rất cao nên phản biện cũng rất khó khăn, sau nhiều lần bị từ chối thì mới có cơ hội được sửa và hoàn thiện bài.

Trong lúc nộp bài và chờ đợi tạp chí đánh giá bài có đủ chất lượng không, em cực kì hồi hộp, vì những lần như thế sẽ là 1 lần đo sự tiến bộ của của nhóm.

Nhưng em cũng thấy rất may mắn vì biên tập viên cuối cùng đã nhận thấy kết quả bài nghiên cứu của mình có giá trị cao, nên đã cho mình cơ hội được phản biện.

Trước khi nộp vào Palgrave Communications, bản thảo của bài thực tế cũng đã bị từ chối bởi tạp chí Nature Sustainability. Mặc dù vậy, họ cũng đánh giá bài rất cao và gợi ý nộp lại vào tạp chí khác."

Không từ bỏ, có lẽ đấy là điều đã giúp Hoàng vượt qua các khó khăn đó. Ngày còn ở APU, chúng tôi từng cùng làm thêm tại nhà ăn của trường.

Ngay trong công việc rửa bát, Hoàng cũng đã luôn là người chăm chỉ, năng động, luôn sắp xếp công việc một cách khoa học khi đi làm đúng giờ và biết cách rửa bát siêu nhanh. Chẳng dễ dàng gì để có thể sống xa nhà, vừa học, vừa làm thêm, và sau đó tiếp tục vượt qua thạc sĩ, có bài nghiên cứu đầu tay, và tiếp tục chương trình tiến sĩ. 


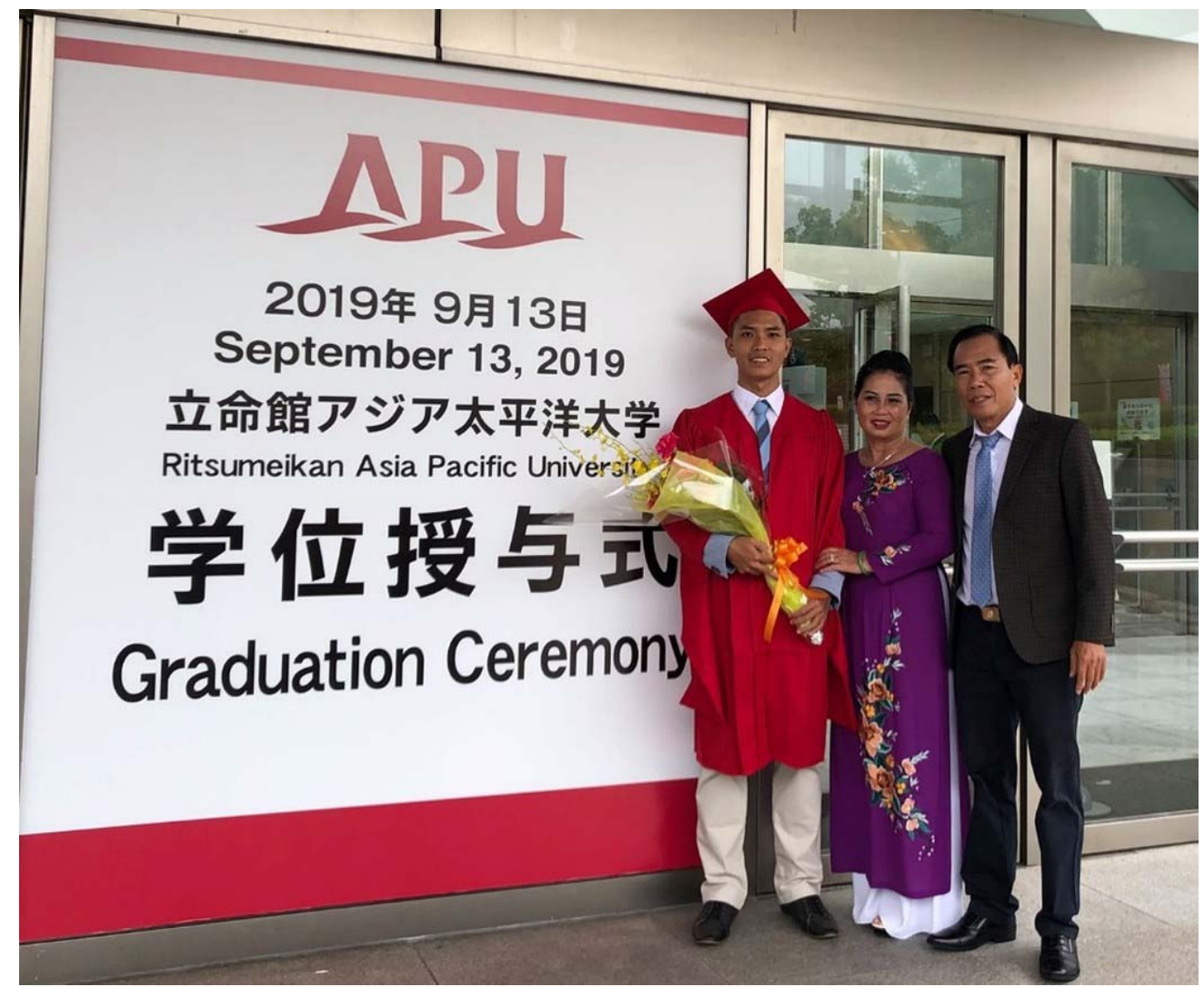

Nguyễn Minh Hoàng và gia đình (Ảnh do Nguyễn Minh Hoàng cung cấp)

Hoàng chia sẻ: “Đồng nghiệp, bạn học và gia đình là điểm tựa của em. Những lúc gặp khó khăn trong quá trình viết bản thảo, bị từ chối, nộp lại, và mãi cuối cùng là trả lời phản biện, mọi người đã động viên em rất nhiều để có thêm nhiều niềm tin và dũng cảm để tiếp tục.

Anh Hồ Mạnh Tùng (đồng tác giả liên lạc) và chị Nguyễn Tô Hồng Kông đã luôn hỗ trợ, bọc lót sửa sai cho em để hoàn thiện bản thảo.

Còn thầy Vương Quân Hoàng (tác giả dẫn dắt) đã rất tận tình chỉ dạy cách cải thiện bản thảo cho hợp lý, và thúc đẩy cả 3 anh chị em trẻ trong nhóm không nhụt chí sau mỗi thư từ chối. Mặc dù cũng hay bị ăn mắng nhưng nếu không có kỷ luật có phần khắc kỷ ấy của đội ngũ, có lẽ em cũng khó có thể đối diện với thất bại tốt như vậy."

Khi tôi mới vào làm thêm tại bếp ăn của trường, Hoàng đã là người có kinh nghiệm trong khu rửa bát. Cậu ấy đã giúp tôi rất nhiều.

Đến bây giờ, cậu ấy cũng một lần nữa lại "dạy" tôi biết thêm một chút về Kitakyushu. Đối với Hoàng, hành trình của cậu ấy mới chỉ vừa bắt đầu, cậu còn cần hoàn thiện hơn nữa để có thể tiếp tục con đường mình đã chọn. 
Nhưng cũng như sự phát triển bền vững của Kitakyushu là kết quả của việc hợp tác - phối hợp giữa chính quyền, tư nhân, và người dân, Hoàng và các đồng tác giả chắc chắn sẽ có thể thành công hơn nữa với đam mê, ý chí, tiềm năng hiện tại.

\section{Tài liệu tham khảo:}

Vuong, Q. H., Ho, M. T., Nguyen, H. K. T., \& Nguyen, M. H. (2019). The trilemma of sustainable industrial growth: Evidence from a piloting OECD's Green city. Palgrave Communications, 5, 156, DOI: 10.1057/s41599-019-0369-8. *URL: https//www.nature.com/articles/s41599-019-0369-8 